\title{
Fósforo reativo: Arraste superficial sob chuvas simuladas para diferentes coberturas vegetais
}

\author{
Luciano G ebler', Ildegardis Bertol'2, Roger R. Ramos², \\ José A. S. Louzada ${ }^{3} \&$ David J. Miquelluti ${ }^{2}$
}

\begin{abstract}
RESU M O
O fósforo é um elemento químico chave para a qualidade da água, agindo principalmente como gatilho desencadeador das florações algais. A principal fonte de fósforo nas pequenas bacias rurais advém da agricultura feita nas encostas das bacias, podendo chegar de várias formas ao corpo d'água, porém as formas mais impactantes são o fósforo reativo total e o dissolvido. A forma dissolvida é a que apresenta maiores riscos pois pode percorrer distâncias comparativamente maiores do que o fósforo reativo nos sedimentos em suspensão que podem acabar depositados ao longo do caminho. Portanto, este trabalho visa avaliar se diferentes coberturas do solo por culturas anuais podem interferir no arraste destas formas de fósforo, afetando o risco da degradação dos recursos hídricos das pequenas bacias rurais. Apesar de não ter havido diferença significativa entre os tratamentos, verificou-se sazonalidade ao longo do experimento representando uma estação de cultivo. Isto significa que houve variação do nível de risco, uma vez que, no terço inicial das primeiras chuvas, o risco de arraste de fósforo na enxurrada foi mais elevado em relação a períodos chuvosos mais distantes da época de plantio/fertilização, tornando-se possível avaliar o risco à bacia de forma sazonal e não anual.
\end{abstract}

Palavras-chave: pequenas bacias rurais; gestão do ambiente agrícola; contaminantes de origem agrícola

\section{Reactive phosphorus: Surface transport under simulated rainfall for different vegetation cover}

\begin{abstract}
A B STRACT
Phosphorus is a chemical element considered key to water quality, mainly acting as a trigger of algal blooms. The main source of phosphorus in small rural basins is agriculture practiced in the slopes of the basins. This phosphorus can come in various forms to the water body, but the most striking ones are the total and dissolved reactive phosphorus. The dissolved form has higher risks, because it can cover distances comparatively larger than the reactive phosphorus in suspension which can be deposited al ong the path. This study sought to determine if different coverage of annual crops can interfere in the transport of these forms of phosphorus, affecting the risk of degradation of water resources of small rural watersheds. Although there was no significant difference between treatments, but seasonality was verified al ong the experiment representing a growing season. This means that there was also some variation in the level of risk, since, in the first third of the first rains, the risk of entrainment of phosphorus in runoff was higher in relation to rainy periods more distant from the planting/fertilization period, making possible to assess the risk to the watershed in a seasonal way rather than annual.
\end{abstract}

Key words: small rural watersheds, management of the agricultural environment, contaminants from agricultural sources

\footnotetext{
${ }^{1}$ Embrapa U va e Vinho. BR 285, KM 115, CP 1513, CEP 95200-000, Vacaria, RS. Fone: (54) 3231-8300. E-mail: Iugebler@cnpuv.embrapa.br ${ }^{2}$ Centro de Ciências Agroveterinárias (CAV), U niversidade do Estado de Santa Catarina (U D ESC). Avenida Luiz de Camões 2090, CEP 88520-000, Lages, SC. Fone: (49) 2101-9235, 2101-9154. E-mail: a2ib@cav.udesc.br; ramosrogerrobert@hotmail.com; a2djm@cav.udesc.br IPH-UFRGS. CP 15029, CEP 91501-970, Porto Alegre-RS. Fone: (51) 3308-6672. E-mail : louzada@iph.ufrgs.br
} 


\section{INTRODUÇÃO}

Os nutrientes nitrogênio e fósforo, presentes nos fluxos decorrentes de enxurradas ocorridas sobre solos agrícolas, são, reconhecidamente, as principais fontes não pontuais de contaminação química de recursos hídricos (Pote et al., 1996; Bertol et al., 2004a; Lewis \& Wurtsbaugh, 2008). Diferente do nitrogênio que pode ser metabolizado diretamente da atmosfera por algumas espécies de algas azuis e bactérias, o fósforo é considerado a chave destas fontes, pois, é normalmente o elemento químico limitante para o desenvolvimento da biota nos corpos d'água (Hart et al., 2004).

Os principais riscos envolvem a eutrofização de corpos d'água com consequiente piora da qualidade da bacia hidrográfica (Daniel et al., 1994; McIsaac et al., 1995; Oliveira et al., 2010), danos econômicos (Colacicco et al., 1989) e à saúde humana (Avalos et al., 2009). Em água, os limites para que estes processos sejam desencadeados situam-se entre $0,001 \mathrm{e}$ $0,3 \mathrm{mg} \mathrm{L}^{-1}$, considerados baixos em relação à concentração de fósforo encontrada na porção de solo agrícola perdido por evento de erosão (Barbosa et al., 2009) e mesmo em relação a atual legislação brasileira (CONAMA, 2005). Ao mesmo tempo, esta legislação não reconhece o elemento fósforo como um possível contaminante químico de solo (CONAMA, 2009), reforçando a percepção do produtor rural de que a fertilização agrícola, quando orientada a este elemento, só deve obedecer a critérios produtivos e econômicos, desconsiderando as questões ambientais.

Estando o fósforo sob diversas formas no solo, deve-se observar sua origem, os mecanismos necessários envolvidos para promover seu deslocamento até algum ponto que possa causar problema e quais formas de danos resultariam disso (Haygarth \& Sharpley, 2000). Dentre as formas de transporte, o escoamento superficial vem sendo estudado como o meio de transporte massivo e de velocidade, que muitas vezes, com um simples evento de precipitação pluviométrica intensa, é suficiente para atingir o nível de dano estabelecido para os recursos hídricos de uma região pelo arraste de fósforo (Sharpley, 1995; Shigaki et al., 2007).

Lombardi Neto \& Moldenhauer (1992) citam experiências na África do Sul onde $25,4 \mathrm{~mm} \mathrm{~h}^{-1}$ seriam chuvas consideradas com energia erosiva suficiente para provocar transporte de solo e, por extensão, o fósforo reativo nele contido.

Apesar da maior quantidade de fósforo carreado pela erosão hídrica estar presente nos sedimentos, arrastados ou em suspensão no fluxo de água (Gérard-Marchant et al., 2005; Barbosa et al., 2009), rapidamente ele se deposita no solo, ao longo de um declive mais longo ou irregular, reduzindo o risco de causar grande impacto na bacia, fora de seu local de origem (McIsaac et al., 1995). Mesmo assim, se a forma reativa ligada aos sedimentos, componente do fósforo reativo total (FRT), atinge o corpo d'água em volume expressivo, ele acaba depositado em seu leito, reagindo com a água ao longo do tempo (Silva \& Toledo, 1997; Souza et al., 2007), ao invés de causar uma liberação imediata do elemento às algas presentes.

O fósforo na forma dissolvida, por outro lado, permanece difuso no fluxo da enxurrada por distâncias maiores. Apesar de apresentar concentração inferior àquela encontrada no FRT, o fósforo reativo dissolvido (FRD), pode disparar sozinho o processo degradativo em corpos d'água, produto de uma enxurrada. Isto se dá, pela pronta disponibilização do fósforo na forma iônica dissolvido em água, representando maior risco de impacto ambiental na bacia (Daniel et al., 1994; GérardMerchand, 2005).

Esta fonte de risco vem aumentando com a expansão de sistemas de manejo do solo como a semeadura direta e outros sistemas conservacionistas baseados somente em cobertura vegetal. Nesses sistemas a concentração de fósforo vinculada aos sedimentos deixa de ser a fonte mais importante de contaminante e o FRT passa a ser, quase na sua totalidade, o FRD (Shigaki et al., 2007).

Ao descrever o sistema de plantio direto Lopes et al. (2010) recomendam cuidado quanto ao prazo, pois indica que nos primeiros cinco anos de conversão de uma área de cultivo tradicional para a semeadura direta há uma demanda maior por fósforo, com praticamente nenhuma sobra mas, à medida em que as plantas formam uma camada de "palhada" orgânica sobre a superfície, resultado da ciclagem orgânica do fósforo do perfil do solo e da deposição continuada do adubo fosfatado aplicado na superfície, passa a ocorrer o contrário, ou seja, excesso de disponibilização do P.

Bertol et al. (2010) apontam que, devido a fatores como esses, existe um grande potencial para haver dano a recursos hídricos, proveniente de formas de fósforo originadas em áreas de semeadura direta, mesmo que em áreas sem adição prévia de adubação.

Mesmo no caso de áreas com cultura perene, como a cultura da macieira, por exemplo, onde o revolvimento total de solo não é tecnicamente recomendado após o pomar estar implantado, o efeito da cobertura pode estar provocando o mesmo fenômeno, ainda não devidamente registrado pela pesquisa. Por outro lado, o maior efeito de retenção física provocado pela estabilidade da área ao longo do tempo, em termos de manejo do solo, também pode estar proporcionando as barreiras físicas necessárias para a retenção do fósforo reativo, por meio do favorecimento da infiltração de água no solo, reduzindo o risco direto aos mananciais superficiais (Leite et al., 2004).

Pela dificuldade da retenção ou retirada do fósforo dissolvido, diversos autores concordam que a ação preventiva é a forma mais eficaz de reduzir o risco de um possível dano ambiental, seja agindo na redução das fontes em áreas sensíveis nas bacias, seja por meio do manejo integrado das áreas agrícolas (Lopes et al., 2007), porém faltam estudos que indiquem o comportamento dessas formas de fósforo reativo no ambiente brasileiro e os melhores meios para seu manejo.

O objetivo deste trabalho foi quantificar o arraste de fósforo reativo total e dissolvido na água de escoamento superficial, sob diferentes culturas herbáceas anuais em um Cambissolo e sob regime de chuvas intensas simuladas.

\section{Material e MÉTODOS}

O experimento foi conduzido durante os meses de dezembro de 2009 e maio de 2010, numa sequência de quatro chuvas 
simuladas, executadas nos dias 18/12/2009, 28/01/2010, 03/03/ 2010 e 15/05/2010, numeradas de um a quatro, acompanhando o estágio de desenvolvimento das culturas, em uma área experimental do Centro de Ciências Agroveterinárias, da Universidade do Estado de Santa Catarina (CAV-UDESC), na região de Lages, SC, situada na latitude $27^{\circ} 49^{\prime}$ Sul e longitude $50^{\circ} 20^{\prime}$ Oeste, numa altitude de 937 m, sobre Cambissolo Húmico alumínico léptico argiloso (EMBRAPA, 2002).

O clima também foi caracterizado segundo Köeppen, como $\mathrm{Cfb}$ (Peel et al., 2007) e chuvas acumuladas se situam na faixa de $1600 \mathrm{~mm}$ ano $^{-1}$ (Bertol et al., 2004b).

Seguindo a metodologia aplicada por Gobbi (2009), 10 parcelas experimentais foram estabelecidas e distribuídas ao acaso, porém ordenadas na forma de cinco tratamentos, cada qual com uma repetição espacial. Em quatro dos tratamentos utilizou-se a semeadura direta sob os cultivos de: soja solteira em cultivo convencional (A), consórcio de milho e feijão semeado na entrelinha em sistema tradicional (B), feijão solteiro em cultivo convencional (C), milho solteiro em cultivo convencional (D) e, adicionalmente, um tratamento em solo sem cultivo, com a superfície totalmente descoberta (E), simulando a situação ambientalmente crítica.

Foram avaliadas as contribuições de fósforo reativo segundo a estrutura das plantas cultivadas, utilizando-se fertilizantes agrícolas segundo recomendação para cada cultura (ROLAS, 2004).

Para esta etapa foi escolhida a área mais homogênea possível visando à implantação das parcelas e a declividade média do terreno ficou em $0,13422 \mathrm{~m} \mathrm{~m}^{-1}$ e o desvio padrão amostral em $0,00601 \mathrm{~m} \mathrm{~m}^{-1}$.

A campo foi utilizado um equipamento simulador de chuva modelo Swanson (Swanson, 1965), com aspersores de chuva VEEJET 80100 (15 para os experimentos em questão), distribuídos em 10 braços rotatórios e distribuição helicoidal numa espiral concêntrica, com diâmetro de 15 m, cobrindo uma área de $176,71 \mathrm{~m}^{2}$ por chuva simulada.

O aparelho foi ajustado para liberar em torno de $64 \mathrm{~mm} \mathrm{~h}^{-1}$ de precipitação de água proveniente de açude, testada quimicamente para determinar a contribuição de fósforo da fonte. Esta precipitação é condizente com a intensidade máxima de chuvas de uma hora para um período de retorno de 15 anos nas regiões de Lages e Campos Novos, SC (Cardoso et al., 1998).

Cada parcela amostral apresentava uma área de $38,50 \mathrm{~m}^{2}$, delimitadas por placas galvanizadas com as dimensões de 30 $\mathrm{cm}$ de altura (cravadas em torno de $10 \mathrm{~cm}$ no solo), $11,00 \mathrm{~m}$ lineares no comprimento do declive e 3,50 $\mathrm{m}$ lineares na largura da parcela. Na parte inferior foi instalada a estrutura coletora na forma de funil, que reunia toda a água de escoamento superficial da parcela em um único ponto, sendo conduzido por um cano de $75 \mathrm{~mm}$ de diâmetro e $6 \mathrm{~m}$ de comprimento, até o ponto de coleta (Bertol et al., 2004b; Amaral et al., 2008; Engel et al., 2009). Entre as parcelas foi mantido um espaçamento de 3,5 m para posicionamento do simulador de chuvas (Figura 1).

A água foi coletada em frascos plásticos de boca larga, com volume de $700 \mathrm{~mL}$ e armazenada sob refrigeração a $4,0^{\circ} \mathrm{C}$, até a execução das análises químicas para o fósforo reativo total e dissolvido (FRT e FRD). Utilizou-se a medição colorimétrica da

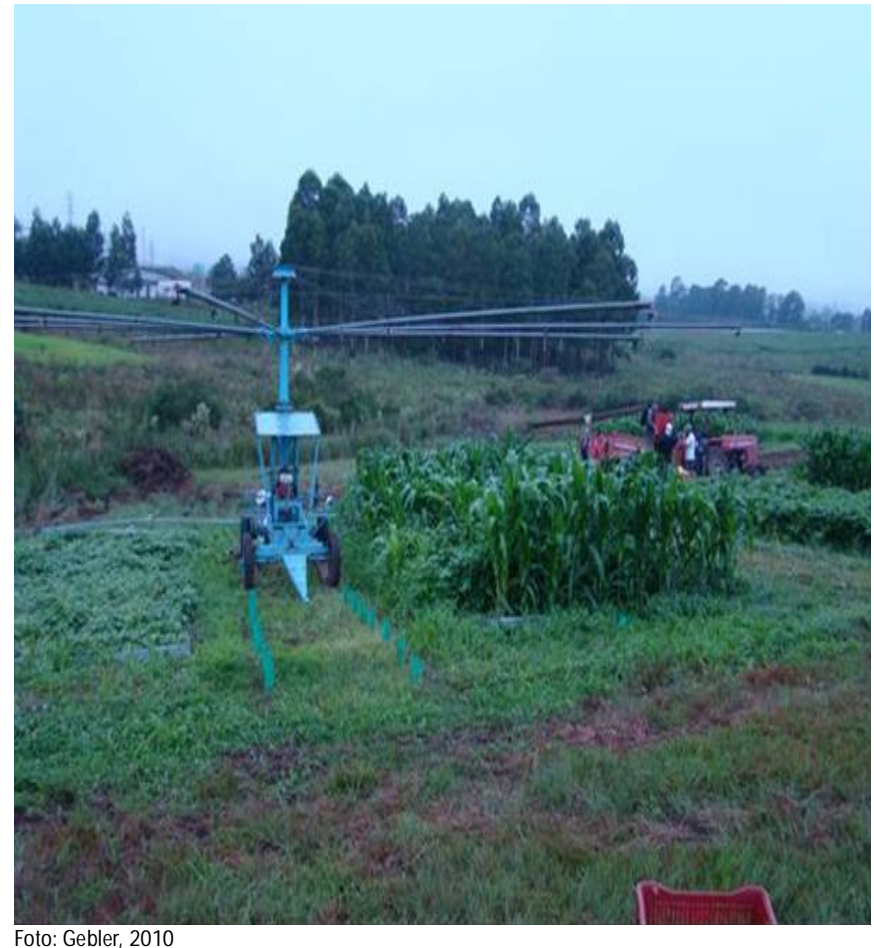

oto: Gebler, 2010

Figura 1. Exemplo do posicionamento do simuladore parcelas experimentais

reação química pelo método do ácido ascórbico em amostras com e sem filtração $(\varnothing<0,45 \mu \mathrm{m})$, conforme Phosphorous (1998).

Em referência aos valores obtidos aplicou-se a análise estatística com os softwares Assistat ${ }^{\circledR}$ e Statistical Analysis System - SAS ${ }^{\circledR}$ (SAS, 2003), além da construção de gráficos com os softwares Microsoft Office Excel $2007^{\circledR}$ e Sigmaplot ${ }^{\circledR}$.

As análises estatísticas foram baseadas no $\mathrm{SAS}^{\circledR}$, realizadas com os dados de todas as unidades experimentais, de acordo com o delineamento em blocos casualizados com repetição e implantadas com um modelo linear de análise de variância com medidas repetidas no tempo (Littel et al., 2006).

As comparações entre os valores médios nos diferentes tratamentos em cada tempo de leitura foram testadas utilizandose o teste Tukey a 5\% (Steel et al., 1997), tal como para a obtenção das equações de regressão para os tempos de leitura em cada tratamento.

Para se atender às pressuposições teóricas implícitas dos testes, foi necessário se transformar a variável analisada somando-se uma unidade aos seus valores originais e se obtendo, a seguir, a função logaritmo natural (transformação logarítmica), conforme sugerido pela análise descritiva dos dados. Todas as análises foram procedidas através do procedimento MIXED (Littel et al., 2006) do software computacional estatístico $\mathrm{SAS}^{\circledR}$.

\section{RESULTADOS E DISCUSSÃO}

\section{FRT em culturas anuais}

Os resultados indicaram que o fósforo reativo é por demais depende da aplicação de fertilizante, uma vez que o fósforo 
natural na região apresenta teores bastante baixos, segundo o tipo de solo do local (EMBRAPA, 2002), reduzindo ou eliminando sua influência, conforme Pote et al. (1999).

Os principais carreamentos de fósforo reativo total ocorreram durante as primeiras chuvas, sendo que suas concentrações atingiram valores médios entre 0,001 a $0,006 \mathrm{mg}$ $\mathrm{L}^{-1}$, faixa considerada suficiente para desencadear o desenvolvimento de algas em corpos d'água (Daniel et al., 1994; McIsaac et al., 1995, Correll, 1998). Entretanto, a concentração e o tipo de $\mathrm{P}$ na enxurrada são fatores que dependem fortemente do ambiente e do manejo (Hart et al., 2004; Bundy et al., 2001), afetando também o risco ambiental, visto que somente após o contaminante se misturar com a água da bacia, é possível determinar se a diluição seria ou não suficiente para haver o dano.

Desta forma, pequenas bacias com grande área utilizada para agricultura e com corpos d’água de pequeno volume, podem ser impactadas mais facilmente que bacias com rios maiores ou menor área agrícola proporcional, concordando com Sharpley (1995).

Na Tabela 1 são apresentadas as médias totalizadas de FRT por etapa de chuva simulada e para cada tratamento, quandoé possível avaliar a evolução do experimento.

Tabela 1. Média de fósforo reativo total (FRT) em $\mathrm{g} \mathrm{ha}^{-1}$ para uma chuva de $1 \mathrm{~h}$ de duração

\begin{tabular}{lccrc}
\hline \multirow{2}{*}{ Tratamento } & \multicolumn{4}{c}{ Etapa de coleta } \\
\cline { 2 - 5 } & Chuva 1 & Chuva 2 & \multicolumn{1}{c}{ Chuva 3 } & Chuva 4 \\
Soja & 24,76293 & 15,57561 & 6,16137 & 20,39161 \\
Consórcio & 25,51077 & 13,73096 & 17,67713 & 21,45154 \\
Feijão & 22,00516 & 10,52073 & 28,10583 & 26,13979 \\
Milho & 17,76222 & 14,33563 & 6,30526 & 23,63465 \\
Solo descoberto & 11,95946 & 18,57384 & 43,31714 & 164,8449 \\
\hline
\end{tabular}

Observa-se que as parcelas que apresentavam solo descoberto (tratamento E), aumentaram constantemente os teores de FRT disponibilizados, ao longo das chuvas, evento que pode ser explicado pelo excesso de chuvas nas fases iniciais do experimento, fora do momento das coletas,o que teria "lavado" o fósforo reativo desses locais.

Posteriormente, o regime de chuvas tendeu a épocas de pouca precipitação, mantendo o fósforo para ser coletado nos momentos do experimento. Este comportamento de perda de fósforo sob volume excessivo de chuvas e de manutenção do fósforo em período sem chuvas, também foi observado em experimentos conduzidos por Sharpley et al. (1981) e por Pote et al. (1999), sob diversas condições, nos Estados Unidos.

Verificou-se que a concentração de FRT reduziu em todos os tratamentos que contaram com cobertura vegetal da primeira para a segunda coleta e após o que se constatou variação de comportamento, fato também explicado pela evolução vegetativa das culturas, do primeiro para o segundo teste, haja vista que durante a primeira coleta as culturas ainda estavam em estágio inicial, com grandes áreas de solo descoberto. $\mathrm{Na}$ segunda coleta, aproximadamente 30 dias após a primeira, as parcelas de A a D se mantinham completamente cobertas, reduzindo o impacto direto da gota da chuva com o solo e a movimentação do solo na superfície do terreno, oferecendo maior resistência ao fluxo da enxurrada, reduzindo significativamente os teores de FRT, sobretudo nas parcelas B e C.

A partir da terceira coleta verificou-se variação de valores de FRT coletados nas parcelas B e C nas quais havia, respectivamente, consórcio de milho-feijão e feijão solteiro, pois as plantas de feijoeiro foram colhidas por arranquio sem resteva, revolvendo parcialmente a superfície do solo e o deixando, ainda, exposto a erosão pela chuva simulada.

Por fim, no momento da quarta chuva todas as culturas já haviam sido colhidas por meio de arranquio, o que provocou aumento acentuado nos teores de fósforo disponível sobre o solo; entretanto, nas parcelas B e C, como não houve movimentação nesta etapa e na chuva anterior já ter sido retirada parte do fósforo reativo da área, os teores de FRT chegaram a apresentar pequena redução nas amostras coletadas.

Analisando o gráfico da Figura 2, no qual foram desconsiderados os valores de FRT das parcelas de solo descoberto, foi possível reapresentar a evolução do fósforo nas parcelas com cobertura visando analisar melhor se houve influência do tipo de cobertura no arraste do FRT.

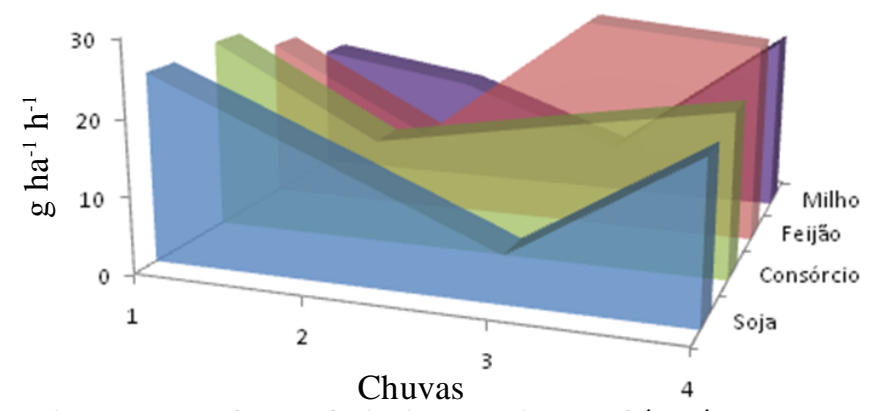

Figura 2. Evolução do fósforo reativo total (FRT) nas áreas com cobertura vegetal durante asquatro coletas do experimento

Este comportamento também foi descrito por Barbosa et al. (2009), em uma série de cinco chuvas simuladas, em que o teor de P na enxurrada decaiu ao longo das quatro primeiras chuvas, enquanto ainda havia cobertura vegetal; apesar disto, durante a ocorrência da quinta chuva após a colheita e mesmo com o solo coberto com os resíduos das plantas, os teores de $\mathrm{P}$ aumentaram.

Aplicando a análise estatística das médias do FRT, observou-se que o nível de significância das médias para todas as análises foi positivo para $5 \%$ de probabilidade, no teste de Tukey.

Para fósforo reativo total somente o tratamento E (solo descoberto), apresentou diferença significativa em comparação com os demais, que também não diferiram entre si para este nível de significância. Mesmo quando o tratamento $\mathrm{E}$ foi desconsiderado, verificou-se que não houve diferença significativa nas médias dos tratamentos $\mathrm{A}, \mathrm{B}, \mathrm{C}$ e D a nível de significância de 5\% Tukey demonstrando que o tipo de cobertura não afeta o transporte do FRT.

Quando analisado o impacto causado ao experimento pelas diferentes chuvas ao longo do tempo, verificou-se que apenas a última chuva apresentou diferença significativa reforçando a importância do uso de cobertura de solo agrícola, de maneira geral, sob regime de chuvas intensas. 
Analisando individualmente as culturas bloqueadas no tempo de coleta, as coletas 1 e 4 diferiram das coletas 2 e 3 , aspecto justificado pela presença de vegetação massiva em diferentes períodos, mesmo com o revés da área de feijão já colhida, contra as médias das áreas descobertas nos períodos 1 e 4 .

Também foi detectada interação entre as médias de tratamento versus blocos, para o período da coleta 3 , quando as parcelas com feijão solteiro (C) diferiram das de soja (A) e milho (D) porém as parcelas de consórcio (B) não diferiram das demais.

Esses resultados são corroborados pelo proposto em Bertol et al. (2010), cuja cobertura vegetal é citada como uma das formas de se impedir o arraste de fósforo, desde que acompanhadas por outras práticas de contenção física e por manejo do solo, principalmente em áreas manejadas sob semeadura direta.

Portanto, uma vez que a teoria do filme apresentada em Zhang et al. (1997) parece atender às questões envolvidas no arraste de fósforo reativo total em solos do sul do Brasil, o processo erosivo inicial resultante da chuva, a desagregação, seria restrito pela cobertura vegetal (Bertol et al., 2010), porém teria menor importância do que práticas de contenção mecânica, como curvas de nível ou camalhões, similares aos encontrados nas áreas de fruticultura, para a contenção do FRT com baixa presença de fósforo reativo solúvel (FRS).

Tais conclusões podem afetar, sobremaneira, bacias localizadas em regiões de clima tropical que permitam mais de um cultivo por estação e o risco de chuvas intensas possa afetar e atingir o solo descoberto recém-adubado, que aumenta e chega a dobrar em relação às regiões de clima temperado (Hart et al., 2004). Algumas regiões no sul do Brasil que se encaixam na condição de clima tropical, seriam as regiões litorâneas de SC e RS, além da região oeste desses dois estados.

\section{FRD em culturas anuais}

Além do FRT analisou-se, também, a disponibilidade do fósforo reativo dissolvido (FRD) e, por diferenciação, o fósforo reativo suspenso (FRS), quando necessário.

Com o agrupamento dos dados notou-se que o tratamento $\mathrm{E}$, apesar de apresentar valores acima dos demais para o FRT, não manteve os mesmos patamares em relação ao FRD, o que pode ser creditado ao maior volume de particulados de solo na enxurrada e, consequentemente, maior volume de FRS. Este comportamento condiz com aquele descrito por Whiters et al. (2001), e assim os valores de equilíbrio na solução da água da enxurrada permanecem similares aos dos demais tratamentos (Figura 3).

Foi possível verificar, com exceção para parcelas de solo descoberto, que apenas numa pequena parte do ano nas bacias rurais o FRD representou grande parte do FRT demonstrando que, mesmo em condições de solo com cobertura, a enxurrada proveniente dessas áreas pode provocar prejuízos aos corpos d'água a grandes distâncias, uma vez que esta parcela do fósforo permanece dissolvido na água da enxurrada por longo tempo, concordando com Pote et al. (1999).

A análise estatística das médias do FRD, estruturada como delineamento em blocos casualizados com repetições,

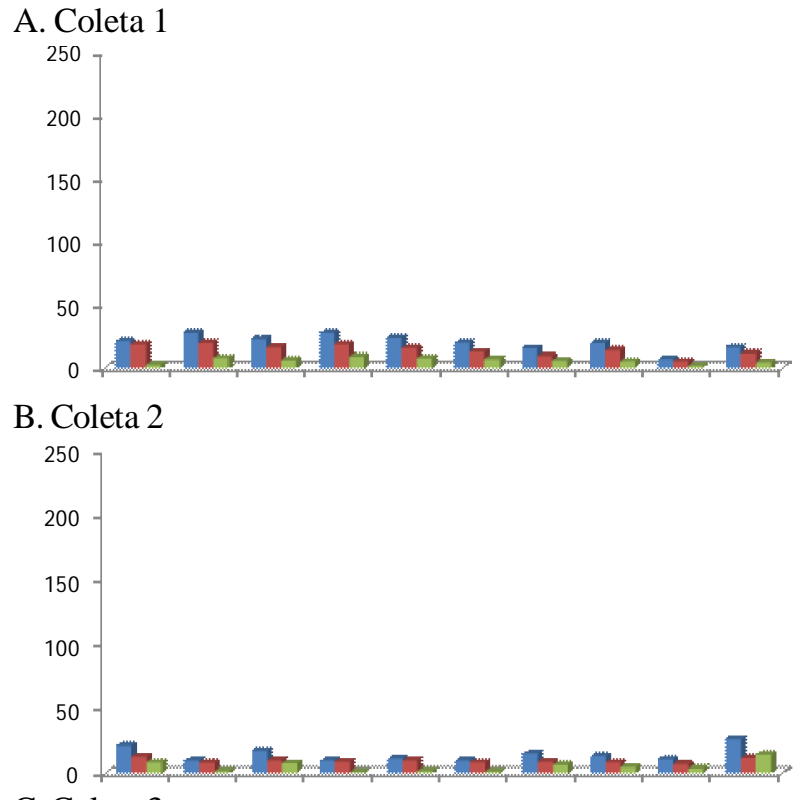

C. Coleta 3

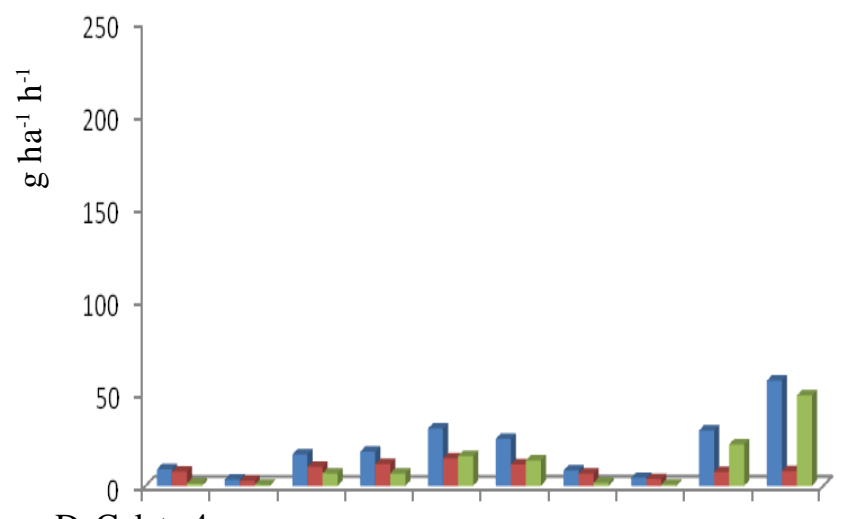

D. Coleta 4

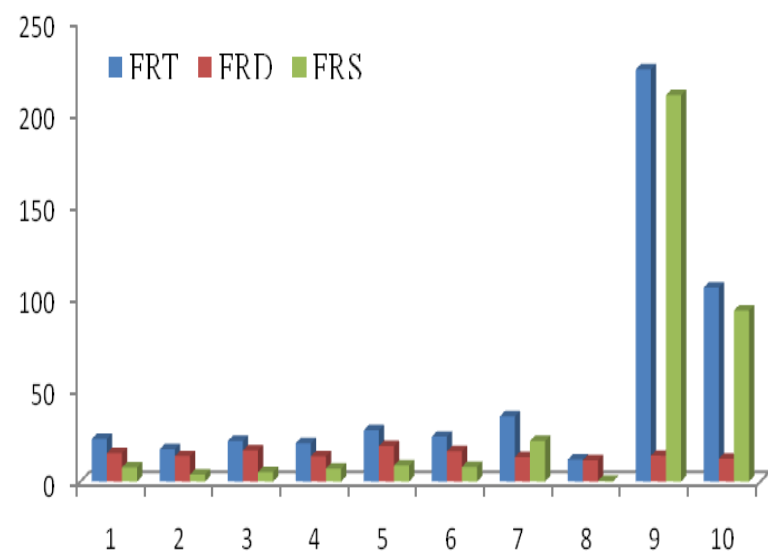

Figura 3. Comportamento das formas de fósforo reativo observadas ao longo da Etapa Il incluindo solo descoberto, $A$ - 1 e 2; B -3 e 4; C - 5 e 6; D - 7 e 8; E - 9 e 10

apresentou significância a nível de 5\% (Tukey) para as médias dos tratamentos, para as médias dos blocos, e a interação tratamento versus blocos.

Em relação aos tratamentos, as parcelas B e C não apresentaram diferença significativa entre si, da mesma forma que as parcelas D e E; entretanto, cada uma dessas duplas apresentou diferença significativa entre si demonstrando que o tipo de manejo influenciou a presença de FRD na enxurrada; 
já o tratamento A não apresentou diferença significativa para nenhum dos demais tratamentos.

Analisando as médias dos blocos referentes à distribuição das chuvas ao longo do experimento, houve repetição do ocorrido com o FRT, em que os resultados das coletas 2 e 3 apresentaram diferença significativa em relação a 1 e a 4 cuja explicação ocorre da mesma forma.

A análise de maior interesse foi a interação entre blocos e tratamentos demonstrando que a evolução do dossel das plantas apresentou grande diferença em relação ao tempo de desenvolvimento das culturas. Para tanto, o tratamento A (soja), foi o pior tratamento durante a execução da primeira coleta enquanto os tratamentos D (milho) e E (solo descoberto), foram os melhores. Uma das causas foi o fato da parcela com soja ter apresentado problemas de germinação e baixo crescimento inicial em que parte do adubo aplicado pode ter ficado exposta. Entretanto, as interações seguintes demonstraram que a soja não só se recuperou em relação aos demais tratamentos, como na coleta 3 passou a ser o tratamento com menor liberação de fósforo reativo solúvel, enquanto a parcela de feijão $(\mathrm{C})$, recém-colhido, passou a ser o pior resultado comprovando a influência do dossel no equilíbrio das formas de fósforo reativo.

Neste caso, Bundy et al. (2001) já alertavam que as práticas de controle de FRT e FRD podem ser diferenciadas; entretanto, dever-se-ia observar o FRD, por apresentar maior risco direto aos corpos hídricos.

Bundy et al. (2001), ainda sugerem que, inclusive, algumas práticas de manejo podem promover antagonismos nas concentrações de FRD em relação ao FRT na enxurrada porém, ainda assim, o potencial poluidor do $\mathrm{P}$ para os recursos hídricos se mantém contrariando, muitas vezes, o proposto por Barbosa et al. (2009) e Langdale et al. (1985), que afirmam que o manejo pode ser suficiente como uma das formas de reduzir o risco de contaminação das recursos hídricos por fósforo.

Por fim, na quarta coleta não houve diferença significativa entre nenhum dos tratamentos, embora fosse prevista uma diferença maior nas parcelas recém-colhidas; este resultado, porém, está em consonância com o observado por Barbosa et al. (2009), tendo como explicação a "lavagem" do pouco fósforo ainda reativo, pela sequência de chuvas (Sharpley et al., 1981; Pote et al., 1999) e a fixação do fósforo ao solo.

Retirando-se o efeito das parcelas de solo descoberto (E), a fim de avaliar mais profundamente as diferenças entre os tratamentos vegetativos, pôde-se observar melhor o comportamento em cada coleta (Figura 4).

Neste caso, a análise estatística do FRD para as médias dos tratamentos ainda usando o teste de Tukey a 5\% de probabilidade, demonstrou que é mantida a relação anterior, quando o tratamento D (milho), resultou como o de menor fluxo de saída de FRD da parcela, enquanto tanto o B (consórcio) quanto o $\mathrm{C}$ (feijão), foram considerados os piores tratamentos. Novamente o tratamento $F$ não apresentou diferença significativa com ambos os grupos.

Esta diferença foi vista como o efeito do menor período vegetativo do feijão, que foi colhido mais cedo, permitindo maior arraste de fósforo reativo ao longo das quatro coletas enquanto as demais parcelas ainda estavam vegetadas e não manuseadas.

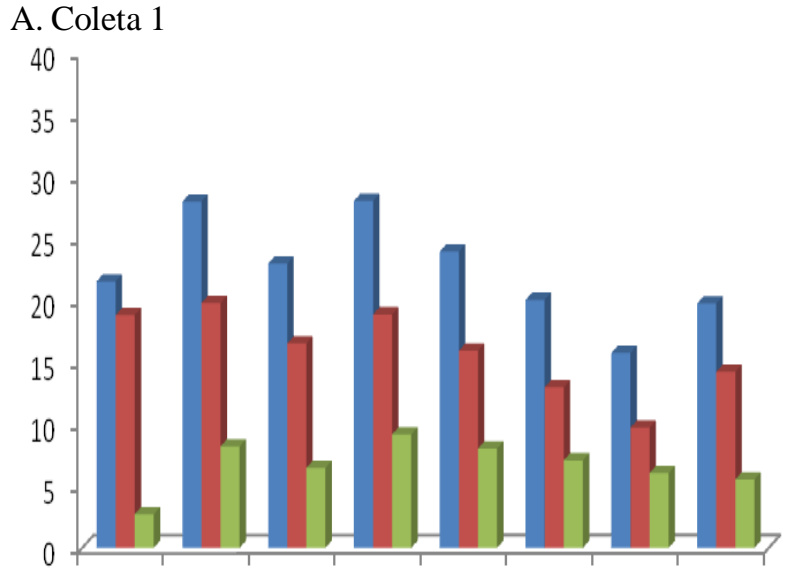

B. Coleta 2
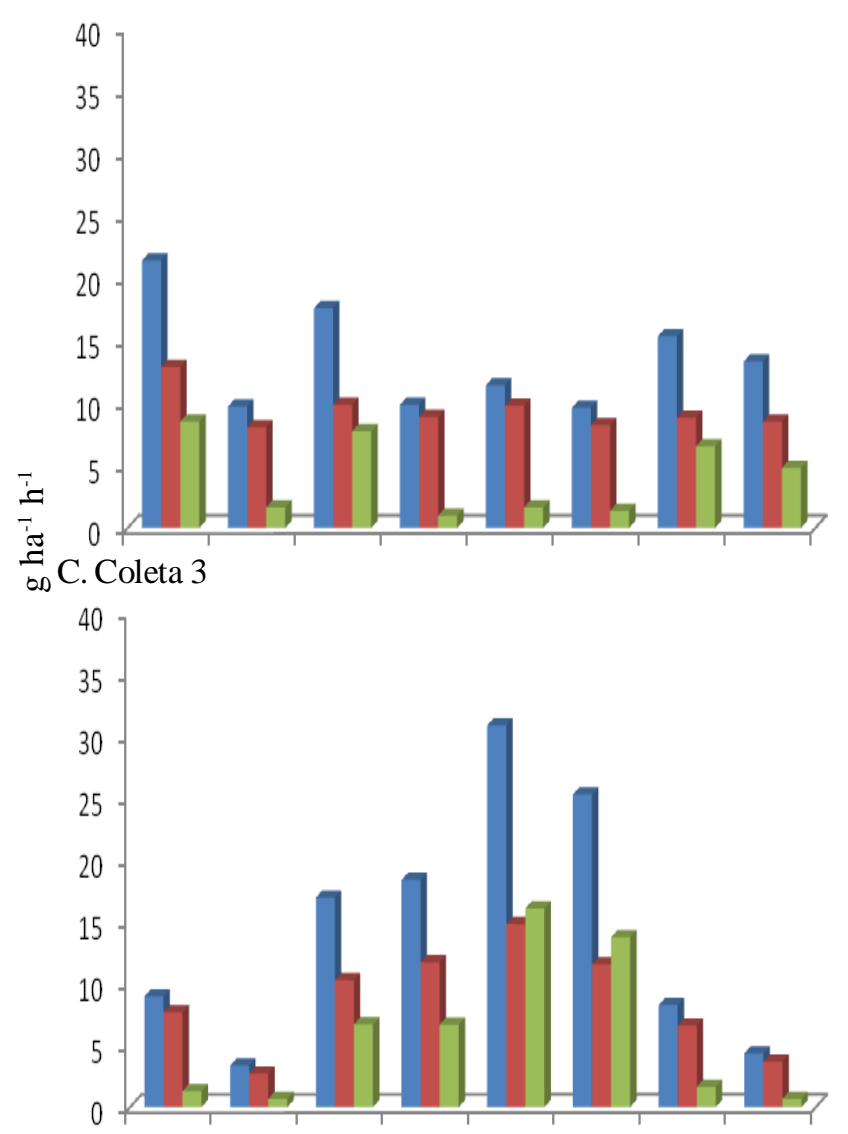

D. Coleta 4

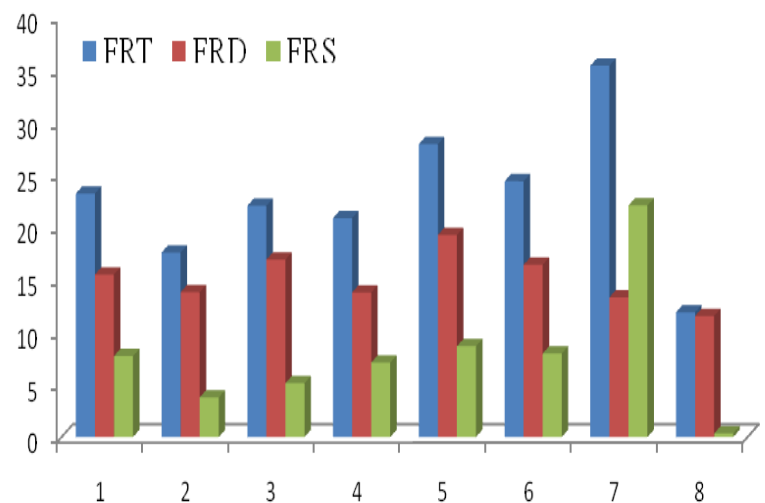

Figura 4. Comportamento das formas de fósforo reativo observado ao longo da Etapa II sem solo descoberto (A 1 e 2 ; B -3 e 4; C - 5 e 6; D - 7 e 8) 


\section{Modelos descritivos de comportamento de FRD e FRT para culturas anuais}

Uma vez que a coleta 2 foi o momento no qual havia maior possibilidade de interferência da ação da vegetação sobre o transporte do fósforo reativo dissolvido, utilizaram-se esses dados para a construção de modelos descritivos para cada cobertura e sua respectiva análise de regressão. Nessas equações a variável que afeta a concentração de fósforo na enxurrada $(\mathrm{Y})$ é o tempo (T), conforme apresentado na Tabela 2.

Tabela 2. Curvas dos modelos de concentração de fósforo reativo dissolvido (FRD) na enxurrada sob interferência da co bertura vegetal

\begin{tabular}{llc}
\hline Cobertura & Modelo & $\mathbf{R}^{2}$ \\
A - Soja & $Y=0,0827+0,01696 * \mathrm{~T}-0,00030 * \mathrm{~T}^{2}$ & 0,84 \\
B - Consórcio & $Y=0,02851+0,01838 * \mathrm{~T}-0,00030 * \mathrm{~T}^{2}$ & 0,95 \\
C - Feijão & $Y=0,0491+0,0175 * \mathrm{~T}-0,00030 * \mathrm{~T}^{2}$ & 0,95 \\
D - Milho & $Y=0,0838+0,01812 * \mathrm{~T}-0,00030 * \mathrm{~T}^{2}$ & 0,95 \\
E - Solo & $Y=0,04641+0,01903 * \mathrm{~T}-0,00030 * \mathrm{~T}^{2}$ & 0,95 \\
\hline
\end{tabular}

A aplicação do mesmo cálculo e a tentativa de geração de modelos para o fósforo reativo total, não lograram o mesmo êxito demonstrado pelos valores de $\mathrm{R}^{2}$ inferiores ao FRD, conforme a Tabela 3 .

Tabela 3. Curvas dos modelos de concentração de fósfoto reativo total (FRT) na enxurrada sob interferência da cobertura vegetal

\begin{tabular}{llc}
\hline Cobertura & Modelo & $\mathbf{R}^{2}$ \\
A - Soja & $Y=0,1405+0,01794 * \mathrm{~T}-0,00033 * \mathrm{~T}^{2}$ & 0,74 \\
B - Consórcio & $Y=0,06582+0,01960 * \mathrm{~T}-0,00033 * \mathrm{~T}^{2}$ & 0,75 \\
C - Feijão & $Y=0,04722+0,01894 * \mathrm{~T}-0,00033 * \mathrm{~T}^{2}$ & 0,88 \\
D - Milho & $Y=0,1615+0,0166 * \mathrm{~T}-0,00033 * \mathrm{~T}^{2}$ & 0,91 \\
E - Solo & $Y=0,1777+0,01899 * \mathrm{~T}-0,00033 * \mathrm{~T}^{2}$ & 0,51 \\
\hline
\end{tabular}

Este fato se deve, provavelmente, à presença intensa de particulados na enxurrada (FRS), dificultando que o fósforo atingisse o mesmo equilíbrio apresentado para o fósforo reativo dissolvido, de vez que havia apenas a presença da forma ionizada do elemento, condizendo com o afirmado por Whiters et al. (2001). De todos os valores o feijão e o milho apresentaram um $\mathrm{R}^{2}$ possível de ser aplicável (> 85\%).

Apesar desta diferença detectada pela curva de regressão para a coleta 2 , na média dos resultados de todas as coletas do experimento, foi possível notar que o hábito de crescimento (rasteiro, ereto ou arbustivo), não apresentou diferenças significativas no período total estudado, embora tenha havido diferenças de pico de crescimento e cobertura de solo ao longo dos meses, como no caso do feijão e sua expressão máxima na coleta 2, para o FRT.

Não houve diferença significativa para o FRD em nenhum momento entre os tipos de cobertura, sendo que esta expressão diferenciada entre as duas formas de fósforo, concorda com Bundy et al. (2001).

\section{Conclusões}

1. A cobertura vegetal do solo agrícola é fator determinante para redução do risco de contaminação de mananciais por arraste do fósforo reativo total, mas exerce relativamente pouco efeito na contenção do fósforo reativo dissolvido.

2. Não houve diferença significativa entre os diferentes tipos de cultura de grãos utilizados atualmente, considerando-se apenas o tipo de cobertura como fator de controle.

3. Os cultivos anuais de verão, apesar de apresentarem baixa correlação com a estrutura da planta, podem apresentar diferenças temporais segundo o manejo, podendo influir na disponibilidade de fósforo reativo total em águas de enxurrada, variando a classificação do risco ambiental nas bacias.

4. O fósforo reativo solúvel pode variar na composição do fósforo reativo total, segundo o volume de sedimentos em suspensão, que interage com o fósforo reativo, mas pode ser a parte mais representativa do fósforo no fluxo da enxurrada em situações de solo com intensa cobertura vegetal, incrementando o risco ambiental envolvido.

\section{LITERATURA CITADA}

Amaral, A. J.; Bertol, I.; Cogo, N. P.; Barbosa, F. T. Redução da erosão hídrica em três sistemas de manejo do solo em um cambissolo húmico da região do planalto sul-catarinense. Revista Brasileira de Ciência do Solo, v. 32, p.2145-2155, 2008.

Avalos, J. M. M.; Fouz, P. S.; Vázquez, E. V.; González, A. P.; Bertol, I. Crop residue effects on organic carbon, nitrogen and phosphorous concentrations and loads in runoff water. Communications in Soil Science and Plant Analysis, v.40, p.200-213, 2009.

Barbosa, F. T.; Bertol, I.; Luciano, R. V.; Gonzales, A. P. Phosphorous losses in water and sediments in runoff of the water erosion in oat and vetch crops seed in contour and downhill. Soil and Tillage Research, v.106, p.22-28, 2009.

Bertol, I.; Guadagnin, J. C.; Cassol, P. C.; Amaral, A. J.; Barbosa, F. T. Perdas de fósforo e potássio por erosão hídrica em um inceptissol sob chuva natural. Revista Brasileira de Ciência do Solo, v.28, p.485-494, 2004a.

Bertol, I.; Leite, D. Guadagnin, J. C.; Ritter, S. R. Erosão hídrica em um nitossolo háplico submetido a diferentes sistemas de manejo sob chuva simulada: perdas de nutrientes e carbono orgânico. Revista Brasileira de Ciência do Solo, v.28, p.1045-1054, 2004b.

Bertol, J. O. Rizzi, N. E.; Favaretto, N.; Lana, M. C. Phosphorus loss by surface runoff in no-till system under mineral and organic fertilization. Scientia Agricola. v.67, p.71-77, 2010.

Bundy, L. G.; Andraski, T. W.; Powell, J. M. Management pratice effects on phosphorus losses in runoff in corn production Systems. Journal of Environmental Quality, v.30, p.18221828, 2001.

Cardoso, C. O.; Ulmann, M. N.; Bertol, I. Análise de chuvas intensas a partir da desagregação das chuvas diárias de Lages e Campos Novos (SC). Revista Brasileira de Ciência do Solo, v.22, p.131-140, 1998.

Colacicco, D.; Osborn, T.; Alt, K. Economic damages from soil erosion. Journal of Soil and Water Conservation, v.44, p.3539, 1989. 
CONAMA - Conselho Nacional do Meio Ambiente Resolução n. 357 de 17 de março de 2005. Dispõe sobre a classificação dos corpos de água e diretrizes ambientais para o seu enquadramento, bem como estabelece as condições e padrões de lançamento de efluentes, e dá outras providências. Diário Oficial da União, Brasília, p.58-63, 18 de mar. 2005, Seção 1.

CONAMA - Conselho Nacional do Meio Ambiente Resolução n. 420 , de 28 de dezembro de 2009. Dispõe sobre critérios e valores orientadores de qualidade do solo quanto à presença de substâncias químicas e estabelece diretrizes para o gerenciamento ambiental de áreas contaminadas por essas substâncias em decorrência de atividades antrópicas. Diário Oficial da União, Brasília, p.81-84, 30 dez. 2009, Seção 2.

Correll, D. L. The role of phosphorus in the eutrophication of receiving waters: a review. Journal of Environmental. Quality, v.27, p.261-266, 1998.

Daniel, T. C.; Sharpley; A. N.; Edwards, D. R.; Wedepohl, R.; Lemunyon, J. L. Minimizing surface water eutrophication from agriculture by phosphorous management. Journal of Soil and Water Conservation, v.40, p.30-38, 1994.

EMBRAPA - Empresa Brasileira de Pesquisa Agropecuária. Sistema brasileiro de classificação dos solos. Brasília: Embrapa Produção da Informação, 2002. 150p.

Engel, F. L.; Bertol, I.; Ritter, S. R.; Paz Gonzales, A.; Paz-Ferreiro, J.; Vidal Vázquez, E. Soil erosion under simulated rainfall in relation to phenological stages of soybeans and tillage methods in Lages-SC-Brasil. Soil e Tillage Research, v.103, p. 216-221, 2009.

Gérard-Marchant, P.; Walter, M. T.; Steenhuis, T. S. Simple models for phosphorous loss from manure during rainfall. Journal of Environmental Quality, v.34, p.872-876, 2005.

Gobbi, E. Erosão hídrica em pomar de maçã sob diversas formas de manejo do solo comparadas ao campo natural. Lages: Universidade do Estado de Santa Catarina, 2009. 110p. Dissertação Mestrado

Hart, M. R.; Quin, B. F.; Nguyen, M, L. Phosphorous runoff from agricultural land and direct fertilizer effects: a review. Journal of Environmental Quality, v.33, p.1954-1972, 2004.

Haygarth, P. M.; Sharpley, A. N. Terminology for phosphorus transfer. Journal of Environmental Quality, v.29, p.10-15, 2000.

Langdale, G. W.; Leonard, R. A.; Thomas, A. W. Conservation practice effects on phosphorous losses from southern piedmont watersheds. Journal of Soil and Water Conservation, v.40, p.157-161, 1985.

Leite, D. Bertol, I.; Guadagnin, J. C.; Santos, E. J.; Ritter, S. R. Erosão hídrica em um nitossolo háplico submetido a diferentes sistemas de manejo sob chuva simulada: perdas de solo e água. Revista Brasileira de Ciência do Solo, v.28, p.1033-1044, 2004.

Lewis, W. M.; Wurtsbaugh, W. A. Control of lacustrine phytoplankton by nutrients: Erosion of the phosphrous paradigm. International Review of Hydrobiology, v.93, p.446465, 2008 .

Littel, R.C.; Milliken, G. A.; Stroup, W. W.; Wolfinger, R. D. Schabenberger, O. SAS ${ }^{\circledast}$ for Mixed Models 2.ed. Cary: SAS Institute, v.62, p.1273-1274. 2006.
Lombardi Neto, F.; Moldenhauser, W. C. Erosividade da chuva: sua distribuição e relação com as perdas de solo em Campinas (SP). Bragantia, v.51, p189-96, 1992.

Lopes, A. S.; Wiethölter, S.; Guilherme, L. R. G.; Silva, C. A.. Sistema plantio direto: bases para o manejo da fertilidade do solo. São Paulo: Associação Nacional para Difusão de Adubos, 2010. p.3-37.

Lopes, F.; Merten, G. H.; Franzen, M.; Giasson, E.; Helfer, F.; Cybis, L. F. A. Utilização de P-Index em uma bacia hidrográfica através de técnicas de geoprocessamento. Revista Brasileira de Engenharia Agrícola e Ambiental, v.11, p. 312-317, 2007.

McIsaac, G. F.; Mitchel, J. K.; Hirschi, M. C. Dissolved phosphorous concentrations in runoff from simulated rainfall on corn and soybean tillage systems. Journal of Soil and Water Conservation, v.50, p.383-387, 1995.

Oliveira, M. F. M.; Favaretto, N. Rollof, G.; Fernandes, C. V. S. Estimativa do potencial de perda de fósforo através da metodologia do P-Index. Revista Brasileira de Engenharia Agrícola e Ambiental, v.14, p.267-273, 2010.

Peel, M. C.; Finlayson, B. L.; Mcmahon, T. A. Update world map of the Köeppen-Geiger climate classification. Hidrology and Earth System Sciences, v.11, p.1633-1644, 2007.

Phosphorous. In: Clesceri, L. S.; Greenberg, A. E. Eaton, A. D. Standard methods for the examination of water and wasterwater. 20.ed. Washington: American Public Health Association, 1998. p.123-148.

Pote, D. H.; Daniel, T. C.; Nichols, D. J.; Sharpley, A. N.; Moore Jr., P. A.; Miller, D. M.; Edwards, D. R. Relationship between phosphorus levels in three ultisols and phosphorous concentrations in runoff. Journal of Environmental Quality, v.28, p.170-175, 1999.

Pote, D. H.; Daniel, T. C.; Sharpley, A. N.; Moore Jr., P. A.; Edwards, D. R.; Nichols, D. J. Relating extractable soil phosphorous to phosphorous losses in runoff. Soil Science Society American Journal, v.60, p.855-859, 1996.

ROLAS - Rede Oficial de Análise de Solo e de Tecido Vegetal. Manual de adubação e calagem para os estados do Rio Grande do Sul e Santa Catarina. 10.ed. Porto Alegre: Sociedade Brasileira de Ciência do Solo, 2004. 400p.

SAS Institute Inc ${ }^{\circledR}$ SAS Ver. 9.1 . 3. Cary: SAS Institute Inc. 2003. CD-Rom.

Sharpley, A. Identifying sites vulnerable to phosphorous loss in agricultural runoff. . Journal of Environmental Quality, v.24, p.947-951, 1995.

Sharpley, A. N.; Menzel, R. G.; Smith, S. J.; Rhoads, E. D.; Olness, A. E. The sorption of soluble phosphorus by soil material during transport in runoff from cropped and grassed watersheds. Journal of Environmental Quality, v.10, p.211$215,1981$.

Shigaki, F.; Sharpley, A.; Prochnow, L. I. Rainfall intensity and phosphorus source effects on phosphorus transport in surface runoff from soil trays. Science of Total Environment. v.373, p.334-343, 2007. 
Silva, I. S.; Toledo, M. C. M. Distribuição e fracionamento químico de fósforo em sedimentos do rio Tietê-região de Pirapora do Bom Jesus. Geochimica Brasiliensis, v.11, p.243259, 1997.

Souza, R. A. S. Araújo, S. R.; Jesus, V. A. M.; Marques, J. J.; Curi, N.; Guerreiro, M. C. Frações de fosfato em reservatórios de água em lavras. Ciência eAgrotecnologia, v.31, p.357-365, 2007.

Steel, R. G. D.; Torrie, J. H.; Dickey, D. A.. Principles and procedures of statistics - a biometrical approach. 3.ed. McGraw-Hill: New York, 1997.666p.
Swanson, N. P. A rotating-boom rainfall simulator. Transactions of the American Society Agriculturall Engineering, v.8, p.71$72,1965$.

Whiters, P. J. A.; Clay, S. D.; Breeze, V. G. Phosphorous transfer in runoff following application of fertilizer, manure and sewage sludge. Journal of Environmental Quality, v.30, p.180-188, 2001.

Zhang, X. C.; Norton, D.; Nearing, M. A. Chemical transfer from soil solution to surface runoff. Water Resources Research, v.33, p.809-815, 1997. 